\title{
Sternal dehiscence in patients with moderate and severe chronic obstructive pulmonary disease undergoing cardiac surgery: The value of supportive thorax vests
}

\author{
Sezai Celik, MD, ${ }^{\mathrm{a}}$ Ahmet Kirbas, MD, ${ }^{\mathrm{b}}$ Onur Gurer, MD, ${ }^{\mathrm{b}}$ Yahya Yildiz, $\mathrm{MD},{ }^{\mathrm{c}}$ and Omer Isik, $\mathrm{MD}^{\mathrm{b}}$
}

Objective: Sternal dehiscence after open surgery is a major cause of morbidity and mortality, and chronic obstructive pulmonary disease is a significant risk factor. Therefore, we aimed to determine whether moderate and severe chronic obstructive pulmonary disease had an effect on the development of sternal dehiscence and whether the use of the Robicsek technique for sternal closure along with sternal support vest postoperatively would reduce the incidence of sternal dehiscence in patients with moderate/severe chronic obstructive pulmonary disease undergoing cardiac surgery.

Methods: Two studies were performed. In study 1, 842 patients undergoing cardiac surgery and figure-of- 8 wire closure were retrospectively evaluated in 2 groups: group 1a (328 patients with chronic obstructive pulmonary disease) and group $1 \mathrm{~b}$ (514 patients without chronic obstructive pulmonary disease). In study 2, 221 patients with moderate and severe COPD who were scheduled for open surgery were prospectively enrolled. The Robicsek technique was used for sternal closure. The postoperative thorax support vest was used in 100 patients (group $2 \mathrm{a}$ ), and no additional procedure was applied in 121 patients (group $2 \mathrm{~b}$ ).

Results: In study 1 , the dehiscence rate was significantly higher in group $1 \mathrm{a}(7.9 \%)$ than in group $1 \mathrm{~b}(1.2 \%$; $P<.001$ ), and mortality rates in patients with dehiscence were $53.8 \%$ and $33.3 \%$, respectively. In study 2 , the dehiscence rate was significantly lower in group $2 \mathrm{a}(1 \%)$ than in group $2 \mathrm{~b}(11.5 \% ; P=.002)$. None of the patients with dehiscence in group $2 \mathrm{a}$ died, and $35.7 \%$ of patients died in group $2 \mathrm{~b}$.

Conclusions: The Robicsek technique for sternal closure and the use of a thorax support vest postoperatively are highly effective in preventing sternal dehiscence after cardiac surgery in patients with moderate and severe chronic obstructive pulmonary disease. (J Thorac Cardiovasc Surg 2011;141:1398-402)

Sternal dehiscence after median sternotomy is a serious complication and may lead to prolonged hospitalization, increased cost of care, and significant mortality. ${ }^{1-4}$ Chronic obstructive pulmonary disease (COPD) is one of the major risk factors for sternal dehiscence in patients undergoing cardiac surgery. ${ }^{5-7}$ The benefits of reinforced sternal closure techniques are controversial. Previous studies have shown that reinforced closure of the sternum may decrease sternal dehiscence rate in high-risk patients. ${ }^{8-10}$ In addition, the use of a thorax support vest after the operation has been shown to reduce sternal wound complications. ${ }^{11}$ We evaluated the influence of COPD on the development of sternal dehiscence in patients undergoing cardiac surgery in the first study. In the second study, we evaluated whether the use of a postoperative tho-

From the Thoracic Surgery Division, Thoracic Department, ${ }^{a}$ Thoracic Surgery Division, Cardiovascular Department, ${ }^{\mathrm{b}}$ and Anesthesiology Department, ${ }^{\mathrm{c}}$ Medicana Hospitals Group, Istanbul, Turkey.

Disclosures: Authors have nothing to disclose with regard to commercial support.

Received for publication Aug 9, 2010; revisions received Dec 21, 2010; accepted for publication Jan 24, 2011; available ahead of print March 7, 2011.

Address for reprints: Sezai Celik, MD, Balkan Cad Kiptas Yesilvadi Konaklari, A3 Blok, D: 36, 34000 Umraniye-Istanbul, Turkey (E-mail: siyamie@gmail.com). 0022-5223/\$36.00

Copyright (c) 2011 by The American Association for Thoracic Surgery doi:10.1016/j.jtcvs.2011.01.042 rax support vest along with the Robicsek sternal closure technique would reduce the rate of sternal dehiscence after cardiac surgery in patients with moderate and severe COPD.

\section{MATERIALS AND METHODS}

\section{Selection and Description of Participants}

Two studies were performed. In the first study, we retrospectively evaluated the incidence and mortality of sternal dehiscence after cardiac surgery in patients with and without COPD. In the second study, we prospectively enrolled patients with COPD who were scheduled for open surgery. The studies were performed in the Medicana Hospitals Group in Istanbul, Turkey, and were approved by the Clinical Research Ethics Committee of the hospitals. Written informed consent was obtained from all patients enrolled in the prospective study.

Patients with chronic infectious diseases (eg, brucellosis and hepatitis), emergency sternotomy, repeat sternotomy, prior radio/chemotherapy, off-pump surgery, or previous thoracic trauma were excluded in both studies.

COPD was classified according to American Thoracic Society guidelines. ${ }^{12}$ Moderate COPD was defined as less than $50 \%$ forced expiratory volume in 1 second $\left(\mathrm{FEV}_{1}\right)$ less than $80 \%$ of the predicted value, and severe COPD was defined as less than $30 \% \mathrm{FEV}_{1}$ less than $50 \%$ of the predicted value. Diagnosis of sternal dehiscence was made on the basis of clinical criteria and lateral and posterior-anterior chest radiographs, and multislice computed tomography if required. Isolated sternal dehiscence was defined as "partial or complete dehiscence of skin, soft tissue, and sternum without infection (mechanical, pain, and clicking)." The descriptions proposed by El Oakley and Wright ${ }^{13}$ were used: superficial sternal wound infection as "a redness, swelling, bogginess or frank discharge (blood 


\section{Abbreviations and Acronyms}

$\mathrm{COPD}=$ chronic obstructive pulmonary disease

$\mathrm{FEV}_{1}=$ forced expiratory volume in 1 second

stained or purulent from skin and subcutaneous tissue)" and deep sternal infection as "complete separation of the sternum, mediastinitis, and frank pus discharge from an open wound."

In the interpretation of chest radiographs, sternal dehiscence was defined as a mid-sternal stripe of lucency, sternal wire displacement $(2 \mathrm{~cm}$ of displacement seen in $\geq 2$ wires), and sternal wire breaks. ${ }^{14}$ In computed tomography evaluations, mediastinitis was defined as small air bubbles or an air-fluid level in the mediastinum.

In study 1, 842 patients with and without COPD, who had undergone elective cardiac surgery via midline sternotomy between July 2004 and September 2007, were retrospectively evaluated. The peristernal figureof- 8 wire closure technique had been used in sternal closure in all patients. The patients were analyzed in 2 groups: group 1a (patients with COPD) and group $1 \mathrm{~b}$ (patients without COPD). Furthermore, to evaluate the relation between respiratory functions and sternal dehiscence in patients with COPD, group 1a was divided into 5 subgroups according to predicted $\mathrm{FEV}_{1}$ values.

In study 2, 221 patients with moderate and severe COPD undergoing open surgery between December 2007 and September 2009 were prospectively analyzed. The study was planned for 244 patients, 122 patients for each group. Patients were randomly assigned to 2 groups 1 to 2 weeks before surgery: vest and non-vest. A computer-generated randomization list was used, and individual allocations were placed in sealed envelopes. An external investigator blinded to the allocation sequence picked consecutive allocation envelops for consecutive participants.

The Robicsek closure technique was used in the sternal closure of all patients. The patients were randomly allocated into 2 groups; sternal support vests were used postoperatively in group $2 \mathrm{a}$, and no additional procedure was performed in group $2 b$. The patients were followed up for 6 months.

All patients evaluated in the 2 studies received preoperative physiotherapy for 7 days. Other risk factors associated with sternal dehiscence, including diabetes mellitus, obesity (body mass index $>30 \mathrm{~kg} / \mathrm{m}^{2}$ ), osteoporosis, reexploration for bleeding, and use of bilateral internal thoracic artery grafts, were also analyzed.

\section{Statistics}

Continuous and normally distributed data are expressed as mean \pm standard deviation. Categoric data are shown as percentages. Univariate analysis of categoric data was carried out using the Pearson chi-square and Fisher exact tests for categoric variables, and the unpaired t test for continuous variables. In the prospective study (study 2), analysis was performed in patients who completed the trial. Sternal dehiscence rate was calculated according to COPD severity.

\section{RESULTS}

There were 328 patients with COPD (group 1a) and 514 patients without COPD (group 1b) in study 1. Patient characteristics, comorbidities, procedure-related variables, and duration of hospitalization are shown in Table 1. No significant difference was found between the 2 groups with regard to age, gender, presence of risk factors (eg, osteoporosis, peripheral arterial disease, diabetes, and chronic renal failure), and procedure-related variables $(P>.05)$.
In group 1a (COPD group) and group $1 \mathrm{~b}$ (non-COPD group), 26 of 328 patients $(7.9 \%)$ and 6 of 514 patients $(1.1 \%)$ had a sternal dehiscence diagnosis. The dehiscence rate was significantly higher in the COPD group than in the non-COPD group $(P<.001)$. Although the rates of isolated dehiscence and superficial wound infections were similar between the 2 groups, the rate of deep sternal wound infections was higher in the COPD group than in the non-COPD group $(P<.001)$. Furthermore, COPD severity also had a significant effect $(P=.002)$ on the development of sternal dehiscence. In patients with COPD, sternal dehiscence incidence was $3.5 \%$ (3/85) among patients with an $\mathrm{FEV}_{1}$ value of $60 \%$ to $70 \%$ and $45.4 \%(10 / 22)$ among patients with an $\mathrm{FEV}_{1}$ value of $30 \%$ to $40 \%$ (Figure 1 ).

Debridement and Robicsek closure were performed in all 26 patients with dehiscence in group 1a. Of these 26 patients, $12(46.2 \%)$ improved and $14(53.8 \%)$ died of mediastinitis and sepsis despite all efforts of rewiring and debridement.

In group $1 \mathrm{~b}$ (non-COPD group), 6 (1.1\%) of 514 patients with a sternal dehiscence diagnosis were treated using the same method; 2 of these 6 patients $(33.3 \%)$ died of respiratory insufficiency and sepsis, and 4 of 6 patients $(66.6 \%)$ recovered after the reoperation.

The mortality rate of the COPD group with sternal dehiscence $(53.8 \% ; 14 / 26)$ was significantly higher than the mortality rate of the non-COPD group with sternal dehiscence $(33.3 \%, 2 / 6 ; P<.001)$.

\section{Study 2}

The study was planned for 244 patients, 122 patients for each group. However, only 221 patients were eligible for analysis, because 23 patients withdrew their consents in different phases of the study ( 1 from the non-vest arm and 22 from the vest arm). Twenty-one who withdrew their consents in the vest arm were obese female patients, and 1 was an elderly male patient who found it difficult to wear the vest. The patient who withdrew his consent in the nonvest arm wanted to wear a vest for his chest pain. The power of the study was calculated backward, and it was determined that group sample sizes of 100 and 121 were adequate to achieve $86 \%$ power to detect a difference of $11 \%$ in deep sternal wound complications between the 2 groups.

No significant difference with regard to age, gender, presence of risk factors (eg, osteoporosis, peripheral arterial disease, diabetes, and chronic renal failure), and procedurerelated variables was observed between the 2 groups evaluated in the second study $(P>.05)$ (Table 1$)$. The use of a support vest was associated with a significantly shorter duration of hospitalization ( $13.7 \pm 6.7$ days vs $17.8 \pm 15.4$ days, $P=.03$ ).

With the experimental event ratio as $0 / 100=0$ and the control event ratio as $8 / 121$, the decrease in the relative risk was calculated as 0.066 . Therefore, we estimated that 15 patients would need to be treated to prevent 1 sternal wound complication. 
TABLE 1. Clinical and demographic data of the patients included in the studies

\begin{tabular}{|c|c|c|c|c|c|c|}
\hline & \multicolumn{3}{|c|}{ Study 1} & \multicolumn{3}{|c|}{ Study 2} \\
\hline & $\begin{array}{c}\text { Group 1a } \\
\text { COPD } \\
\mathbf{n}=\mathbf{3 2 8} \\
\end{array}$ & $\begin{array}{c}\text { Group 1b } \\
\text { Non-COPD } \\
\mathbf{n}=\mathbf{5 1 4} \\
\end{array}$ & $\boldsymbol{P}$ & $\begin{array}{c}\text { Group 2a } \\
\text { Vest } \\
\mathbf{n}=\mathbf{1 0 0}\end{array}$ & $\begin{array}{c}\text { Group 2b } \\
\text { Non-vest } \\
\mathbf{n}=\mathbf{1 2 1}\end{array}$ & $P$ \\
\hline $\mathrm{M} / \mathrm{F}(\mathrm{n} / \mathrm{n})$ & $209 / 119$ & $330 / 214$ & .60 & $66 / 34$ & $82 / 39$ & .61 \\
\hline Age (y) & $68.22 \pm 8.31$ & $67.60 \pm 8.52$ & .70 & $66.34 \pm 7.13$ & $68.44 \pm 9.22$ & .78 \\
\hline $\mathrm{EF}<35(\%)$ & $26(8)$ & $51(10)$ & .68 & $5(5)$ & $8(7)$ & .73 \\
\hline \multicolumn{7}{|l|}{ COPD $(\%)$} \\
\hline Moderate & $266(81.1)$ & & & $63(63)$ & $61(50.4)$ & .85 \\
\hline Severe & $62(18.9)$ & & & $37(37)$ & $39(49.6)$ & .87 \\
\hline $\mathrm{BMI}>30 \mathrm{~kg} / \mathrm{m}^{2}(\%)$ & $102(31)$ & 149 (29) & .70 & $28(28)$ & $31(26)$ & .81 \\
\hline NYHA class 3 and $4(\%)$ & $131(40)$ & $221(43)$ & .71 & $39(39)$ & $46(38)$ & .72 \\
\hline DM $(\%)$ & $121(37)$ & $216(42)$ & .63 & $44(44)$ & $57(47)$ & .60 \\
\hline CRF $(\%)$ & $23(7)$ & $36(7)$ & .83 & $8(8)$ & $12(10)$ & .85 \\
\hline $\operatorname{PAD}(\%)$ & $108(33)$ & $190(37)$ & .75 & $27(27)$ & $28(23)$ & .70 \\
\hline Steroid use $(\%)$ & $26(8)$ & $31(6)$ & .23 & $9(9)$ & $10(8)$ & .12 \\
\hline Sternal Osteoporosis (\%) & - & - & - & $34(34)$ & $48(40)$ & .60 \\
\hline CABG $(\%)$ & $233(68)$ & $344(67)$ & & $65(65)$ & $80(66)$ & \\
\hline CABG plus valve $(\%)$ & $20(6)$ & $36(7)$ & & $7(7)$ & $6(5)$ & \\
\hline Valve $(\%)$ & $59(18)$ & $98(19)$ & & $16(16)$ & $18(15)$ & \\
\hline Aortic aneurysm (\%) & $10(3)$ & $21(4)$ & & $5(5)$ & $7(6)$ & \\
\hline Others $(\%)$ & $16(5)$ & $21(4)$ & & $7(7)$ & $8(7)$ & \\
\hline ECC (min) & $126 \pm 38$ & $123 \pm 44$ & .75 & $117 \pm 61$ & $125 \pm 64$ & .80 \\
\hline $\mathrm{AXC}(\min )$ & $75 \pm 25$ & $78 \pm 33$ & .60 & $71 \pm 27$ & $73 \pm 31$ & .65 \\
\hline $\operatorname{IABP}(\%)$ & $10(3)$ & $10(2)$ & .70 & $4(4)$ & $4(3)$ & .71 \\
\hline Ventilation support (h) & $24 \pm 33$ & $24 \pm 37$ & .65 & $24 \pm 38$ & $24 \pm 41$ & .75 \\
\hline Reexploration for bleeding (\%) & $23(7)$ & $41(8)$ & .50 & $5(5)$ & $8(7)$ & .50 \\
\hline Postoperative delirium (\%) & $98(30)$ & $144(28)$ & .80 & $25(25)$ & $40(33)$ & .76 \\
\hline \multicolumn{7}{|l|}{ Hospitalization (d) } \\
\hline ICU stay & $3.5 \pm 4.1$ & $3.8 \pm 4.3$ & .72 & $3.2 \pm 3.6$ & $2.9 \pm 3.2$ & .76 \\
\hline Hospital stay & $15.4 \pm 7.4$ & $17.1 \pm 9.4$ & .80 & $13.7 \pm 6.7$ & $17.8 \pm 15.4$ & .03 \\
\hline
\end{tabular}

COPD, Chronic obstructive pulmonary disease; $E F$, ejection fraction; $B M I$, body mass index; $N Y H A$, New York Heart Association; $D M$, diabetes mellitus; $C R F$, chronic renal failure; $P A D$, peripheral arterial disease; $C A B G$, coronary artery bypass graft; $E C C$, extracorporeal circulation time; $A X C$, aortic crossclamp time; IABP, intraaortic balloon pump; $I C U$, intensive care unit.

Of the 100 patients in group $2 \mathrm{a}$, sternal dehiscence occurred in only $1(1 \%)$, a 67-year-old man with severe COPD. Although the patient had isolated (noninfectious) sternal dehiscence after discharge at the postoperative 17th day, he did not want reoperation and preferred to use the sternal support vest. He showed no clinical deterioration; he was still sterile and clinically stable at the end of the follow-up period (Figure 2). Of the 121 patients in group $2 \mathrm{~b}$ (patients with COPD without vest), isolated dehiscence developed in $3(2.5 \%)$, superficial wound infection developed in $3(2.5 \%)$, and deep sternal wound infection developed in $8(6.6 \%)$. We used titanium bars in 3 patients. After the reoperation, 9 of 14 patients $(64.3 \%)$ recovered, but 5 of 14 patients $(35.7 \%)$ died of mediastinitis and sepsis, although the patients underwent reoperation with bilateral pectoralis major muscle flaps. Although there were no deaths among the patients who wore thorax support vests after the operation, $35.7 \%$ of the patients without a vest died.

The rates of dehiscence and infection are summarized in Table 2. Patients treated with a thorax support vest had

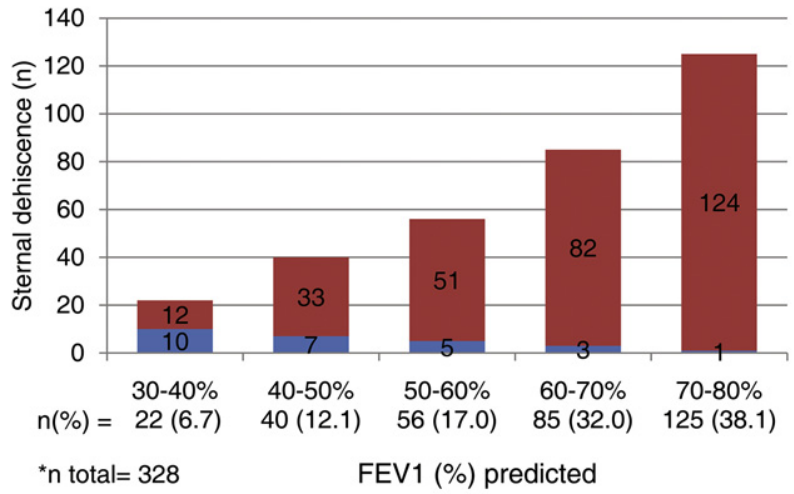

- Patients without sternal dehiscence a Patients with sternal dehiscence FIGURE 1. Incidence of sternal dehiscence in patients with moderate and severe COPD according to $\mathrm{FEV}_{1}$ subgroups. $F E V_{1}$, Forced expiratory volume in 1 second. 


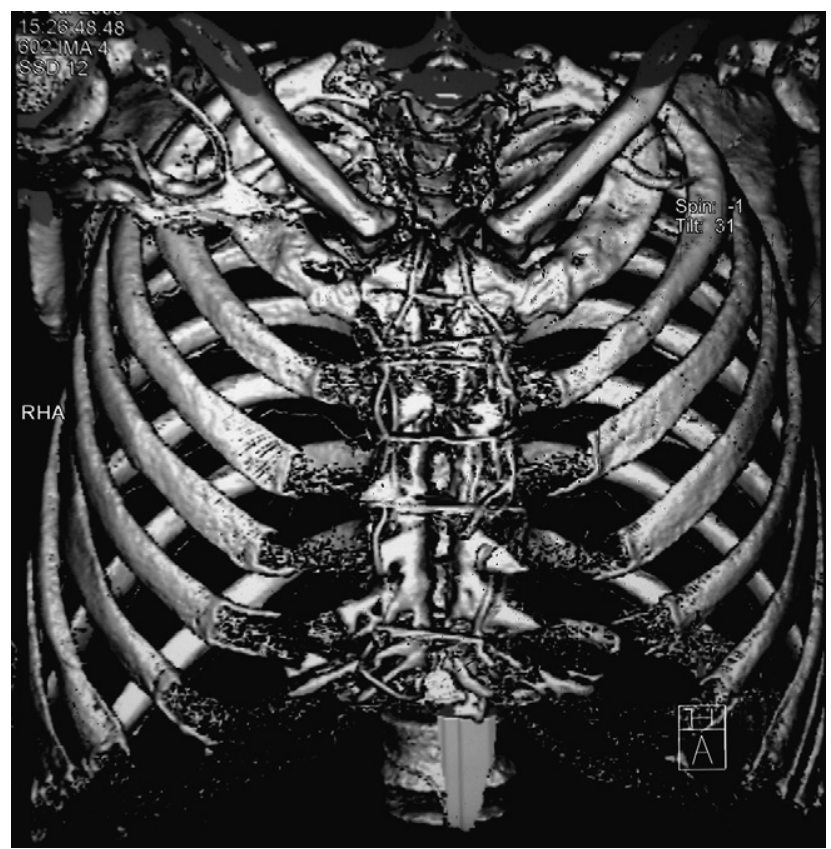

FIGURE 2. Multislice tomography showing the sternal dehiscence after Robicsek closure in a patient from study 2 . The peristernal wires became loose in every level; therefore, they lose their efficiency on the parallel reinforcement sutures bringing the sternum together.

a significantly lower incidence of dehiscence (1\% vs $11.5 \% ; P=.002)$ and deep sternal wound infections $(0 \%$ vs $6.6 \%, P=.009)$; however, the rates of superficial wound infections $(0 \%$ vs $2.5 \%, P=.253)$ and isolated sternal dehiscence ( $1 \%$ vs $2.5 \%, P=.628)$ were similar between the 2 groups.

\section{DISCUSSION}

Sternal dehiscence after cardiac surgery causes significant morbidity and mortality. COPD is one of the most important risk factors for sternal dehiscence, and its prevalence is increasingly frequent in patients undergoing cardiac surgery. COPD incidence was actually $28.4 \%$ among patients who were undergoing open surgery in our

TABLE 2. Incidence and types of dehiscence in both studies

\begin{tabular}{|c|c|c|c|c|c|c|}
\hline & \multicolumn{3}{|c|}{ Study $1(n=842)$} & \multicolumn{3}{|c|}{ Study $2(n=221)$} \\
\hline & $\begin{array}{c}\text { Group 1a } \\
\text { COPD } \\
\mathbf{n}=\mathbf{3 2 8} \\
\end{array}$ & $\begin{array}{c}\text { Group 1b } \\
\text { Non-COPD } \\
\mathbf{n}=\mathbf{5 1 4} \\
\end{array}$ & $P$ & $\begin{array}{c}\text { Group 2a } \\
\text { Vest } \\
\mathbf{n}=\mathbf{1 0 0} \\
\end{array}$ & $\begin{array}{c}\text { Group 2b } \\
\text { Non-vest } \\
\mathbf{n}=\mathbf{1 2 1} \\
\end{array}$ & $\boldsymbol{P}$ \\
\hline ISD & $6(1.8)$ & $3(6)$ & .098 & $1(1)$ & $3(2.5)$ & .628 \\
\hline SSWI & $4(1.2)$ & $1(0.2)$ & .079 & - & $3(2.5)$ & .253 \\
\hline DSWI & $16(4.9)$ & $2(0.4)$ & $<.001$ & - & $8(6.6)$ & .009 \\
\hline Total & $26(7.9)$ & $6(1.2)$ & $<.001$ & $1(1)$ & $14(11.5)$ & .002 \\
\hline
\end{tabular}

$C O P D$, Chronic obstructive pulmonary disease; $I S D$, isolated sternal dehiscence; $S S W I$, superficial sternal wound infection; DSWI, deep sternal wound infection. Data are presented as n $(\%)$ for each group. hospital during the time period of the first study. Because 668 patients were not included in the study according to exclusion criteria, stated as urgent surgery, redo surgery, offpump surgery, and infectious diseases, such as hepatitis and sternal pathologies. Gunen and colleagues ${ }^{15}$ reported that the prevalence of COPD was $18.1 \%$ in smokers aged more than 40 years in a large region in Turkey. Kandemir and colleagues ${ }^{16}$ determined that COPD frequency was $39.2 \%$ in patients undergoing coronary bypass surgery in a region where the majority of the inhabitants were mine workers. Furthermore, we know that most of the patients undergoing coronary bypass surgery have a 30 pack-year smoking history in Turkey, and the rate reaches $80 \%$. This is one of the most important reasons why COPD and coronary artery diseases are prevalent in Turkey.

A prospective study evaluating the rate of sternal dehiscence after cardiac surgery, particularly in patients with moderate and severe COPD, has not yet been presented. However, COPD has been shown to be associated with higher morbidity and mortality rates after coronary artery bypass grafting, ${ }^{5-7}$ and some studies have established a greater risk for experiencing sternal wound complications. ${ }^{1,10}$ Similarly, in the first study, the dehiscence rate was significantly higher in patients with COPD, especially in those with an $\mathrm{FEV}_{1}$ value of $30 \%$ to $40 \%$ of the predicted value.

Sternal instability usually occurs in the first few days or weeks after median sternotomy and may lead to dehiscence because of the fracture of the sternal bone or the sternal wires. ${ }^{1}$ Because of coughing and respiratory movements of the chest wall, the steel wires loosen; the sternal halves separate and cut the sternum into segments. ${ }^{17}$ Therefore, additional measures, such as sternal vests, are needed in the early postoperative period. The Posthorax (Epple Inc, Vienna, Austria), a newly designed thorax support vest, was produced as an additional tool in postoperative care after median sternotomy. ${ }^{11}$

It is important to improve the cough with respiratory physiotherapy and bronchodilators before the surgery. Previous studies have shown that preoperative physiotherapy decreases pulmonary complications after coronary artery bypass grafting, and its continuation prevents pulmonary complications in the postoperative period. ${ }^{18,19}$ Furthermore, discontinuation of smoking and vigorous pulmonary toilet before surgery are essential in preventing postoperative pulmonary complications in patients with COPD. All patients evaluated in both studies received respiratory physiotherapy, including incentive spirometry, deep breathing exercises, expectoration, and bronchodilator therapy for 1 or 2 weeks before surgery and in the postoperative period.

There is no consensus among surgeons on the optimal method for sternal closure, particularly in high-risk patients. However, sternal closure reinforcement techniques versus conventional sternal closure technique have been 
advised in high-risk patients because of the ability to reduce the incidence of sternal dehiscence. ${ }^{8-10}$ Therefore, the Robicsek method still remains the gold standard for highrisk patients according to the literature. In study two, 3 of 9 patients who underwent reoperation and recovered after the development of sternal dehiscence had multiple fractures in the sternum. We treated these patients with titanium bars. Rigid fixation methods are particularly used for this purpose in the reported literature. ${ }^{20}$

We applied the Robicsek closure method to all patients in the prospective study and found that Posthorax use after Robicsek closure significantly decreased the rate of sternal dehiscence and mortality. Gorlitzer and colleagues ${ }^{11}$ were the first to describe and demonstrate the reduction in sternal wound complications after cardiac surgery with Posthorax use. However, comparative rates of sternal wound complications and the efficiency of the vest in high-risk groups have not been reported. It is important that the Posthorax vest ensures anteroposterior stabilization while holding the sternum halves together without creating any unwanted pressure. The Posthorax vest also serves as a shock absorber for the sternum, by the 2 cushions placed longitudinally to the right and left, which is especially helpful when the patient coughs or breathes deeply. Because the Posthorax is an easy to use device and has adjustable fittings, family members and nursing staff easily learn the application of the device. However, the device is still expensive, and it does not seem practical to adjust and use the device in obese female patients.

The primary aim of our study was to evaluate the effects of moderate to severe COPD on the sternal dehiscence rate and whether application of vests decreases the rate of sternal dehiscence. Therefore, we did not evaluate all the risk factors affecting sternal complications. This may be regarded as a limitation of the present study.

\section{CONCLUSIONS}

Moderate to severe COPD is a significant risk factor for sternal dehiscence after cardiac surgery. The use of a thorax support vest after the Robicsek closure method after median sternotomy in patients with moderate and severe COPD undergoing cardiac surgery seems to effectively reduce sternal wound complications and mortality. However, because the use of thorax support vests is not suitable in obese female patients, different treatment alternatives must be considered to decrease sternal wound complications, particularly in those with big breasts.

\section{References}

1. Robicsek F, Fokin A, Cook J, Bhatia D. Sternal instability after midline sternotomy. Thorac Cardiovasc Surg. 2000;48:1-8.

2. Olbrecht VA, Barreiro CJ, Bonde PN, Williams JA, Baumgartner WA, Gott VL, et al. Clinical outcomes of noninfectious sternal dehiscence after median sternotomy. Ann Thorac Surg. 2006;82:902-7.

3. Ståhle E, Tammelin A, Bergström R, Hambreus A, Nyström SO, Hansson HE. Sternal wound complications-incidence, microbiology and risk factors. Eur J Cardiothorac Surg. 199;11:1146-53.

4. Zacharias A, Habib RH. Factors predisposing to median sternotomy complications. Deep vs superficial infection. Chest. 1996;110:1173-8.

5. Cohen A, Katz M, Katz R, Hauptman E, Schachner A. Chronic obstructive pulmonary disease in patients undergoing coronary artery bypass grafting. $J$ Thorac Cardiovasc Surg. 1995;109:574-81.

6. Samuels LE, Kaufman MS, Morris RJ, Promisloff R, Brockman SK. Coronary artery bypass grafting in patients with COPD. Chest. 1998;113:878-82.

7. Medalion B, Katz MG, Cohen AJ, Hauptman E, Sasson L, Schachner A. Longterm beneficial effect of coronary artery bypass grafting in patients with COPD. Chest. 2004;125:56-62.

8. Narang S, Banerjee A, Satsangi DK, Geelani MA. Sternal weave in high-risk patients to prevent noninfective sternal dehiscence. Asian Cardiovasc Thorac Ann. 2009; $17: 167-70$.

9. Cañas-Cañas A, Lima-Cañadas PP, López-Almodóvar LF, Serrano-Martínez F, Paredes-Astillero I, Torres-Crespo MJ, et al. Prophylaxis of sternal dehiscence in obese patients through systematic application of Robicsek closure. Cir Esp. 2005;78: $100-2$.

10. Okutan H, Tenekeci C, Kutsal A. The reinforced sternal closure system is reliable to use in elderly patients. J Card Surg. 2005;20:271-3.

11. Gorlitzer M, Folkmann S, Meinhart J, Poslussny P, Thalmann M, Weiss G, et al. A newly designed thorax support vest prevents sternum instability after median sternotomy. Eur J Cardiothorac Surg. 2009;36:335-9.

12. American Thoracic Society. Standards for the diagnosis and care of patients with COPD. Am J Respir Crit Care Med. 1995;152:S77-121.

13. El Oakley RM, Wright JE. Postoperative mediastinitis, classification and management. Ann Thorac Surg. 1996;61:1030-6.

14. Hayward RH, Knight WL, Reiter CG. Sternal dehiscence. Early detection by radiography. J Thorac Cardiovasc Surg. 1994;108:616-9.

15. Gunen H, Hacievliyagil SS, Yetkin O, Gulbas G, Mutlu LC, Pehlivan E. The prevalence of COPD: first epidemiological study of a large region in Turkey. Eur J Intern Med. 2008;19:499-504.

16. Kandemir O, Buyukates M, Turan AS, Ceylan E, Kurt T, Dogan SM, et al. The results of coronary artery bypass surgery in a region with a high incidence of chronic obstructive pulmonary disease. Turkish J Thorac Cardiovasc Surg. 2007;15:113-7.

17. Sharma R, Puri D, Panigrahi BP, Virdi IS. A modified parasternal wire technique for prevention and treatment of sternal dehiscence. Ann Thorac Surg. 2004;77: 210-3.

18. Hulzebos EH, Helders PJ, Favié NJ, De Bie RA, Brutel de la Riviere A, Van Meeteren NL. Preoperative intensive inspiratory muscle training to prevent postoperative pulmonary complications in high-risk patients undergoing CABG surgery: a randomized clinical trial. JAMA. 2006;296:1851-7.

19. Stiller K, Montarello J, Wallace M, Daff M, Grant R, Jenkins S, et al. Efficacy of breathing and coughing exercises in the prevention of pulmonary complications after coronary artery surgery. Chest. 1994;105:741-7.

20. Huh J, Bakaeen F, Chu D, Wall MJ Jr. Transverse sternal plating in secondary reconstruction. J Thorac Cardiovasc Surg. 2008;36:1476-80. 